DOI: $10.4274 /$ tftr.80037

\title{
Brakial Arter Kanülasyonu Sonrası Gelișen Yüksek Median Sinir Lezyonunun Elektrofizyolojik ve Ultrasonografik Değerlendirmesi
}

\author{
Electrophysiological and Ultrasonographic Evaluation of Median Nerve Injury After \\ Brachial Arter Cannulation
}

\author{
Elif YALÇIN, Burcu ÖNDER, Aydan KURTARAN, Özge YILDIRIM, Müfit AKYÜZ \\ Ankara Fizik Tedavi Rehabilitasyon Eğitim ve Araştırma Hastanesi, Fizik Tedavi ve Rehabilitasyon Kliniği, Ankara, Türkiye
}

\section{Sayın Editör;}

Bilindiği gibi, periferik arteriyal kanülasyon yöntemi uzun yıllardır majör kardiyak operasyonlar sırasında hemodinamik monitorizasyon amacıyla uygulanmaktadır. Femoral, radial, aksillar ve brakial arterler gibi değişik kanülasyon alanları vardır. Tüm bu girişim yerlerinin değişik kardiyak, vasküler ve nörolojik komplikasyonları bilinmektedir (1). Kardiyak operasyonlar sırasında uygulanan bu kanülasyonlara bağlı gelişebilen periferik sinir hasarları nadir görülmekle beraber akılda bulunması gereken bir nörolojik komplikasyondur. Bu nadir görülen komplikasyonu vurgulamak ve ayırıcı tanılar arasında akla gelmesini sağlamak amacıyla median sternotomi sırasında uygulanan brakial arter kanülasyonu sonrası komplikasyon olarak yüksek median sinir lezyonu gelişen bir vakayı sizlerle paylaşmak istiyoruz.

Elli sekiz yaşındaki erkek hastanın başka bir merkezde yapılan poliklinik muayenesinde C8-T1 kök lezyonu ön tanısı ile EMG istemi yapılmıştı. Hastanın kliniğimizde elektrofizyolojik çalışma öncesi yapılan kısa sorgusunda 1 yıl önceki koroner bypass operasyonu sonrası sağ el ve önkolda güçsüzlük ve uyuşukluk şikayetleri olduğu öğrenildi. Göğüs orta hattında median sternotomi skarı mevcuttu.

Elektrofizyolojik çalışmada ulnar ve radial sinir motor ve duyusal ileti çalışmaları normal sınırlarda elde edildi. Median sinir motor iletim çalışmasında ise, abduktör pollisis brevis kasından yüzeyel kayıt elektrotu ile bilek-dirsek altı, dirsek altı-dirsek üstü, dirsek üstüaksilla segmentlerinde oldukça küçük amplitüdlü birleşik kas aksiyon potansiyeli (BKAP) elde edildi. Median sinir duyusal sinir iletim çalışması ortodromik metod ile 2. parmak-bilek ve avuç içi-bilek segmentlerinden yapıldı. İletim hızı yavaşlamış ve duyusal aksiyon potansiyelleri (DAP) normalden ufalmış olarak bulundu. Sağ median sinir önkol ( bilek-antekubital fossa) ve kol (antekubital fossa-aksilla) segmentinde mikst sinir ileti çalışmasına düşük amplitüdlü yanıt alındı. Abduktor pollisis brevis ve pronator teres kaslarının iğne EMG'sinde kronik nörojenik MÜP değişiklikleri izlenmiş olup spontan aktivite izlenmedi. Pronator teres kasından ise iğne kayıtla yine oldukça düşük amplütüdlü BKAP elde edildi. Bu elektrofizyolojik bulgular median sinirin kolda pronator teres kası innervasyonu proksimalinde kronik parsiyel dejenerasyonuna işaret etmekteydi.

Bu bulgular üzerine hastanın alınan ayrıntılı anamnezinde asıl şikayetinin sağ el başparmak ve ikinci parmak arasında cisimleri rahat kavrayamama olduğu anlaşıldı. Muayenesinde ise sağ el başparmak fleksiyon, opposizyon, 1., 2., 3., 4. parmak metakarpofalengeal ve distal interfalangeal eklem fleksiyonunda güçsüzlük vardı. Sağ önkol fleksörlerinde kuvvetsizlik mevcuttu. Duyu bozukluğu minimal hipoestezi şeklinde 1., 2., 3. parmak palmar yüzünde ve 4. parmak lateral tarafında mevcuttu. Ayrıca göğüs orta hattında median sternotomi skarına ek olarak aksillada 
Tablo 1. Sinir iletim çalısması ve iğne EMG bulguları.

\begin{tabular}{|c|c|c|c|c|c|c|}
\hline \multicolumn{2}{|l|}{ Sağ Median } & \multicolumn{2}{|c|}{ Latans (ms) } & \multicolumn{2}{|c|}{ Amplitüd (mV) } & Ileti hızı $(\mathrm{m} / \mathrm{s})$ \\
\hline \multicolumn{7}{|l|}{ Motor } \\
\hline \multicolumn{2}{|l|}{ Bilek-Abduktor pollisis brevis } & \multicolumn{2}{|c|}{4,6} & \multicolumn{2}{|c|}{0,6} & - \\
\hline \multicolumn{2}{|l|}{ Dirsek altı-Bilek } & \multicolumn{2}{|c|}{5,4} & \multicolumn{2}{|c|}{1,3} & 51,1 \\
\hline \multicolumn{2}{|l|}{ Dirsek üstü-Dirsek altı } & \multicolumn{2}{|c|}{7,7} & \multicolumn{2}{|c|}{1,9} & 44 \\
\hline \multicolumn{2}{|l|}{ Aksilla-Dirsek üstü } & \multicolumn{2}{|c|}{7,6} & \multicolumn{2}{|c|}{1,9} & 44 \\
\hline \multicolumn{2}{|l|}{ Erb-Aksilla } & \multicolumn{2}{|c|}{7,4} & \multicolumn{2}{|c|}{1,6} & 45,6 \\
\hline \multicolumn{7}{|l|}{ Duyu } \\
\hline \multicolumn{2}{|l|}{ Avuç içi-Bilek } & \multicolumn{2}{|c|}{3,1} & \multicolumn{2}{|c|}{8,2} & 35,5 \\
\hline \multicolumn{2}{|l|}{ 2.parmak-Bilek } & \multicolumn{2}{|c|}{3,5} & \multicolumn{2}{|c|}{6,9} & 36,7 \\
\hline \multicolumn{7}{|l|}{ Mikst } \\
\hline \multicolumn{2}{|l|}{ Bilek-Antekubital fossa } & \multicolumn{2}{|c|}{3,8} & \multicolumn{2}{|c|}{2,3} & 63,2 \\
\hline Antekubital fossa-Aksilla & & & 8 & 2,1 & & 58,1 \\
\hline Sağ Radial & & Latan & $\mathrm{s}(\mathrm{ms})$ & Amplitüd & & lleti hızı (m/s) \\
\hline Motor & & & & & & \\
\hline Önkol- Ekstansör Indisis Propri & & & .7 & 7,4 & & - \\
\hline Kol-Önkol & & & 6 & 7,1 & & 55,1 \\
\hline Duyu & & & & & & \\
\hline Bilek-1.parmak & & & 3 & 22, & & 56,5 \\
\hline Sağ Ulnar & & Latan & $\mathrm{s}(\mathrm{ms})$ & Amplitüd & & Ileti hızı $(\mathrm{m} / \mathrm{s})$ \\
\hline Bilek- Abduktör Digiti Minimi & & & 2 & 11,0 & & - \\
\hline Dirsek üstü-Bilek & & & 0 & 11,1 & & 52,3 \\
\hline Duyu & & & & & & \\
\hline Bilek-5.parmak & & & 3 & 15 & & 56,9 \\
\hline lğne EMG & & & & & emli Aktiv & \\
\hline & Yorum & Fibrilasyon & Pozitif Keskin Dalga & Amplitüd & Süre & Interferans Paterni \\
\hline Sağ Pronator Teres & Orta inak & 0 & 0 & ++ & ++ & Seyrelme \\
\hline Sağ Abduktor Pollisis Brevis & Orta inak & 0 & 0 & ++ & ++ & Seyrelme \\
\hline Sağ Ekstansör Indisis Proprius & Normal & 0 & 0 & Normal & Normal & Normal \\
\hline Sağ Abduktör Digiti Minimi & Normal & 0 & 0 & Normal & Normal & Normal \\
\hline Sağ Biceps & Normal & 0 & 0 & Normal & Normal & Normal \\
\hline
\end{tabular}

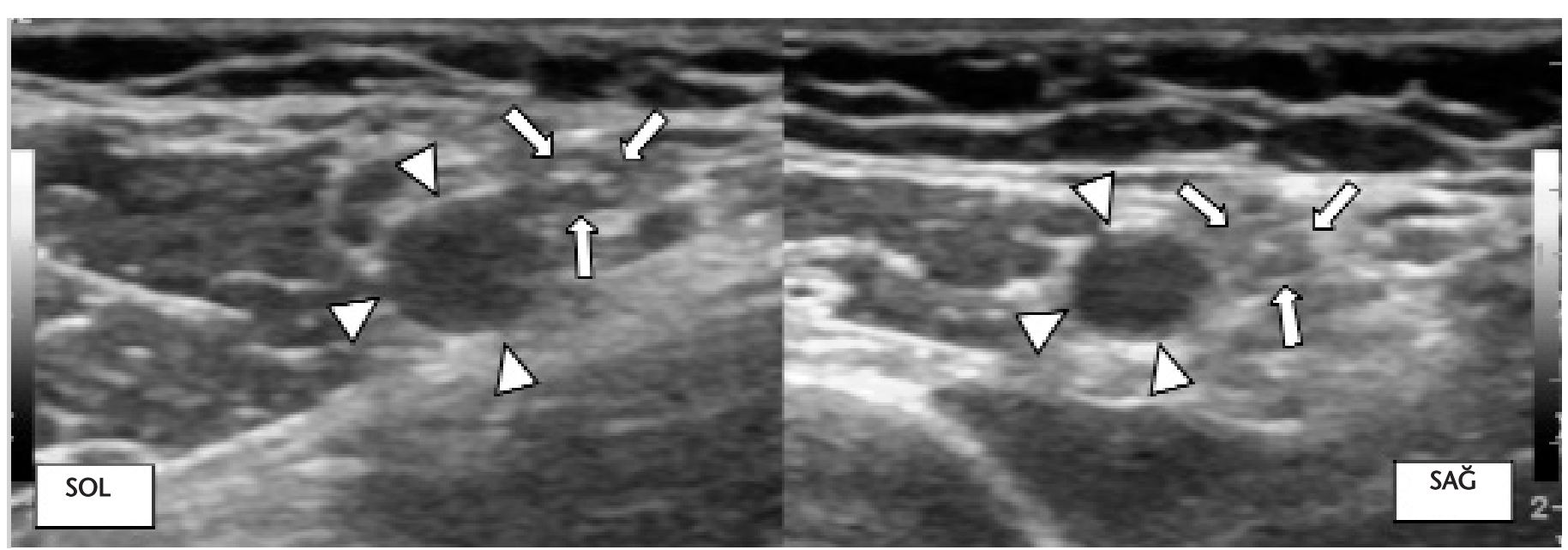

Resim 1. Median sinirin (oklar) aksiller seviyede aksiller arter (okbaşları) komşuluğunda bilateral görünümü.

median sinir trasesine yakın komşulukta $7 \mathrm{~cm}$.'lik başka bir skar izine daha rastlandı. Bu skarın ameliyat sırasında aksilladan yapılan brakial arter kanülasyonuna ait olduğu görüldü.
Hastadan yumruk yapması istendiğinde fleksor pollisis longus, 2. parmağın fleksor digitorum profundus ve tenar bölge kaslarının güçsüzlüğüne bağlı yüksek median lezyonu işaret eden ebe eli 
görünümü mevcuttu. Bu bulgular üzerine aslında median sternotomi sırasında gelişen C8-T1 kök lezyonu ön tanısı ile takip edilen lezyonun elektrofizyolojik çalışma sonucu (Tablo 1) ile tekrar edilen ayrıntılı anamnez ve muayene sonrası tanının aynı operasyon sırasında uygulanan brakial arter kanülasyonuna sekonder gelişen yüksek median sinir lezyonu olduğu anlaşıldı.

Median sinirin aksilladan önkol trasesine kadar yapılan ultrasonografik incelemesinde: median sinirin aksiller arter komşuluğunda sağda karşı tarafa göre ekojenitesinde hafif azalma saptandı ve sınırlarının netliğinde azalma izlendi. Tüm trase boyunca bası yapabilecek patolojik bulgu saptanmadı (Resim 1).

Brakial pleksopati ve periferik sinir lezyonları koroner arter cerrahisi sonrası görülebilecek nadir komplikasyonlardandır. Bu komplikasyonlar median sternotomi sırasında gelişebileceği gibi periferik arter kanülasyonlarına da bağlı gelişebilir. Aksiller kanülasyon sonrasında brakial pleksus lezyonları, brakial arter kanülasyonu sonrasında ise median sinir hasarı gelişebilmektedir (2). Median sternotomiye bağlı olarak ise uygun yapılmayan sternal retraksiyonlar, kırık kosta penetrasyonu veya soğuk uygulamaya bağlı özellikle C8-T1 kök lezyonları görülebilmektedir (3).

Brakial arter kanülasyonlarında insizyon aksiller çukura doğru yapılır. Aksiller olukta median sinir biseps braki kasının iç yanındaki olukta brakial arter ile birlikte seyreder. Bu yakın komşuluk nedeniyle artere yapılan girişimlerde median sinir lezyonu gelişebilmektedir. Kennedy ve ark. (1) brakial arter kanülasyonuna bağlı yüksek median sinir lezyonu oranını \%0,2-1,4 olarak bulmuşlar fakat bu konuda kapsamlı net bilginin az olduğunu belirtmişlerdir. Bu komplikasyona neden olan patolojik durumlar arasında hematom basısı, sinire direk travma, yara yeri iyileşmesine sekonder gelişen fibroz doku sayılabilir. Bu amaçla yapılan median sinirin ultrasonografik incelemesinde median sinire bası yapabilecek patolojik bulguya rastlanmadı.

Median sternotomiye bağlı pleksus yaralanmalarının ise \%2-38 oranında görüldüğü belirtilmektedir ve sıklıkla brakial pleksus alt trunkusları etkilenmektedir $(3,4)$. Bu komplikasyonun daha sık görülmesi daha çok bilinmesine ve ön tanılarda daha çok akla gelmesine neden olur. Bu operasyon sırasında kostosternal birleşkede internal mamarial arterin izlenmesi amacıyla yapılan geniş ekartasyon alt trunkus lezyonuna yol açabilmektedir. Aynı şekilde kolların operasyon sırasında uzun süre sabit aynı pozisyonda gergin tutulması da bu lezyonu arttırabilir. Bu komplikasyondan kaçınmak için ekartasyon işleminin mümkün olduğunca distalden, fazla gergin olmaksızın, aralıkı dinlenme periyotları ile yapılması önerilmektedir (5).

Kardiyak operasyonlar sonrası her hastaya ayrıntılı nörolojik değerlendirme lezyonun erken tanısı ve tedavisi için mutlaka yapılmalıdır. Ayrıca kardiyak operasyonlar sonrası üst ekstremitede gelişebilecek sinir lezyonlarının median sternotomiye sekonder olabileceği gibi yapılan kanülasyon girişimlerine sekonder de olabileceği mutlaka akılda bulundurulmalıdır.

\section{Çıkar Çatışması:}

Yazarlar herhangi bir çıkar çatışması bildirmemişlerdir.

\section{Kaynaklar}

1. Kennedy AM, Grocott M, Schwartz MS, Modarres H, Scott M, Schon F. Median nerve injury: an underrecognised complication of brachial artery cardiac catheterisation? I Neurol Neurosurg Psychiatry 1997;63:542-6.

2. Papadopoulou M, Spengos K, Papapostolou A, Tsivgoulis G, Karandreas $\mathrm{N}$. Intraoperative radial nerve injury during coronary artery surgery-report of two cases. I Brachial Plex Peripher Nerve Inj 2006; $1: 7$.

3. Unlü $Y$, Velioğlu $Y$, Koçak H, Becit N, Ceviz M. Brachial plexus injury following median sternotomy. Interact Cardiovasc Thorac Surg 2007;6:235-7. Epub 2007 Jan 4.

4. Vahl CF, Carl I, Müller-Vahl H, Struck E. Brachial plexus injury after cardiac surgery, the role of internal mammary artery preparation: a prospectivestudy on 1000 consecutivepatients. J Thorac Cardiovasc Surg 1991;102:724-9.

5. Tomlinson DL, Hirsh IA, Kodali SV, Slogoff SV. Protecting the brachial plexus during median sternotomy. I Thorac Cardiovasc Surg 1987;94:297-301. 